\title{
sciforum
}

Conference Proceedings Paper

\section{Climatic influence on atmospheric evaporative demand in Estonia (1951-2015)}

\author{
Fernando Domínguez-Castro, ${ }^{1,}$, Sergio Vicente-Serrano ${ }^{1}$, Jaak Jaagus ${ }^{2}$, Miquel Tomas-Burguera ${ }^{3}$, \\ Marina Peña-Gallardo' ${ }^{1}$ Tim McVicar ${ }^{4}$ \\ Published: 08/11/2017 \\ Academic Editor: Diego Miralles \\ 1 Instituto Pirenaico de Ecología, IPE-CSIC; f.dominguez.castro@gmail.com, svicen@ipe.csic.es, \\ marinapgallardo@ipe.csic.es \\ 2 Institute of Ecology and Earth Sciences, University of Tartu; jaak.jaagus@ut.ee \\ 3 Estación Experimental Aula Dei, EEAD-CSIC, mtomas@eead.csic.es \\ 4 CSIRO Land and Water, tim.mcvicar@csiro.au \\ * Correspondence: f.dominguez.castro@gmail.com, Tel.: +34- 976-369-393
}

\begin{abstract}
Atmospheric evaporative demand (AED) trends at global scale are important to understand the impact of global warming in the hydrological cycle. To shed light on the AED variability in Estonia we have studied the spatial and temporal variability of reference evapotranspiration (ETo) from 1951 to 2015. We have computed $E T_{0}$ from 9 high-quality meteorological stations by means of a Penman-Monteith equation. We have analysed the spatial and temporal variability of $\mathrm{ET}_{0}$ and its main drivers i.e. maximum temperature, minimum temperature, wind speed, sunshine duration, relative humidity and atmospheric pressure. ETo, at annual and country scale, shows a positive and significant trend with a magnitude of change during the studied period of $5.3 \mathrm{~mm}$ decade ${ }^{-1}$, with the highest values during the spring $\left(4.1 \mathrm{~mm}^{\text {decade }}{ }^{-1}\right)$. High significant correlation ( $\mathrm{r}=0.7-0.8)$ has been found among computed $\mathrm{ET}_{0}$ and observed pan evaporation (Epan) during the period 1968-2005. ETo is highly correlated with sunshine (positive), relative humidity (negative) and maximum temperature (positive). Meanwhile sunshine has no significant trend, maximum temperature shows positive and significant trend in all the series and seasons and relative humidity shows significant negative trends in 8 of the 9 series studied in spring.
\end{abstract}

Keywords: ET0; Estonia; climate variability

\section{Introduction}

The Atmospheric evaporative demand (AED) is a key factor in the hydrological cycle. Under the global warming scenario, it is important to evaluate the variability and trend of ADE and its main meteorological drivers i.e. maximum temperature, minimum temperature, wind speed, sunshine duration, relative humidity. McVicar et al. meta-study [1] shows that at global scale AED is increasing with averages of $3.19 \mathrm{~mm}^{\text {decade }}{ }^{-1}$ for Epan (observed pan evaporation) and $1.31 \mathrm{~mm}^{\text {decade }}{ }^{-1}$ for ETo (reference evapotranspiration). Taking into account that differences among regions are large and reanalysis evaporation fields are not reliable [2], regional studies are required to better understand the variability and trends of AED. Few studies have evaluated $\mathrm{E}_{\mathrm{pan}}$ or $\mathrm{ET}_{0}$ above latitudes $55^{\circ} \mathrm{N}$. Golubev et al. [3] provides Epan trends of $-0.3 \%$ decade $^{-1}$ and $-0.18 \%$ decade $^{-1}$ for Siberia (under taiga and forest-steppe vegetation respectively) and $-5.8 \%$ decade $^{-1}$ for North European Russia (under taiga vegetation), during the period 1950 to 1990 . 
The 1st International Electronic Conference on Hydrological Cycle (CHyCle-2017), 12 - 16 November 2017; Sciforum Electronic Conference Series, Vol. 1, 2017

This is the first study about AED in Estonia. Estonia is an eastern European country located among 57.5-60 $\mathrm{N}$ and 58-59.5 ${ }^{\circ} \mathrm{E}$ with an area of $45300 \mathrm{~km}^{2}$ and an altitudinal range from 0 to 318 m.a.s.l. Currently evapotranspiration in Estonia is limited by energy from September to March (precipitation greater than $\mathrm{ET}_{0}$ ) and by water from April to August (ETo greater than precipitation) [1].

\section{Experiments}

\subsection{Data}

We have used monthly precipitation, relative humidity, sunshine duration, temperature, and wind speed series from 9 stations and atmospheric pressure for one station (Tartu) for the period 1951-2015 (Figure 1). All these meteorological series have been quality checked and homogenized with HOMER (HOMogenization softwarE in R) [4].

We have computed ETo for each location from FAO (Food and Agricultural Organization) -56 Penman-Monteith equation [5]. Solar radiation has been estimated from sunshine duration [6]. We must take into account that we have used Tartu atmospheric pressure to compute $\mathrm{ET}_{0}$ in all the stations. Fortunately atmospheric pressure has little weight in the computation of the ETo. We have computed the seasonal (DJF, MAM, JJA, SON) and annual averages of ETo. To explore the general characteristics of the region, a country series have been also computed using the weighted averages of the monthly records for each station based on Thiessen polygons.

Epan has been measured daily at Kuusiku (1989-2005), Tiirikoja (1988-2005) and Tooma (19681996) (Figure 1). The measurements were taken with a GGI-3000 pan that has a surface of $3000 \mathrm{~cm}^{2}$ and a depth of $60 \mathrm{~cm}$. Due to the freezing of the water surface, measurements start around March/May and end in October/November. For this reason only summer averages have been computed.

Trend detection has been performed with Mann-Kendall statistic. The magnitude of change has been computed by a linear regression analysis between time (independent variable) and ETo (or the meteorological variables), the slope of the regression shows the magnitude of change per year.

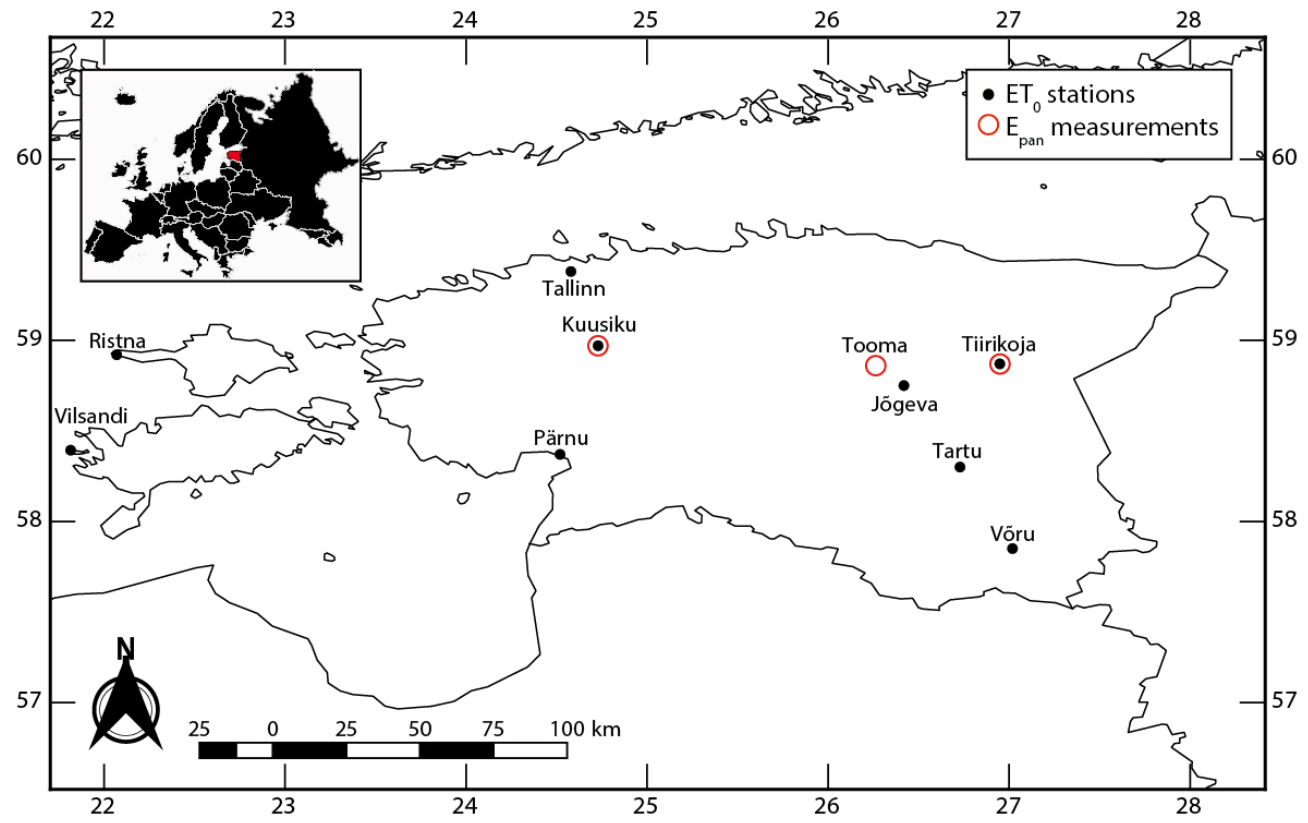

Figure 1. Location of the meteorological series. 
The 1st International Electronic Conference on Hydrological Cycle (CHyCle-2017), 12 - 16 November 2017; Sciforum Electronic Conference Series, Vol. 1, 2017

\section{Results}

Figure 2 shows the evolution of the meteorological variables for the country series at annual scale. Maximum and minimum temperature show a significant positive trend, wind speed shows a significant negative trend whereas relative humidity and atmospheric pressure do not show significant trends. ETo annual scale shows a positive trend with a magnitude of change of $5.3 \mathrm{~mm}$ decade $^{-1}$. This trend is mainly owed to the trend in spring, season in which the magnitude of change is $4.1 \mathrm{~mm} \mathrm{decade}^{-1}$ and to a lesser extent by the summer (1.9 mm decade-1) (Figure 3). On the other hand minor negative trends have been recorded in winter and autumn (Figure 3). At station scale, it is interesting to note that the coastal stations show greater $\mathrm{ET}_{0}$ trends than the inland ones $(3 \mathrm{~mm}$ decade $^{-1}$ in mean) (Figure 4). Most of this difference occurs during the summer, season in which the coastal series have a magnitude of change of $2.5 \mathrm{~mm}$ decade ${ }^{-1}$ greater than inland series.
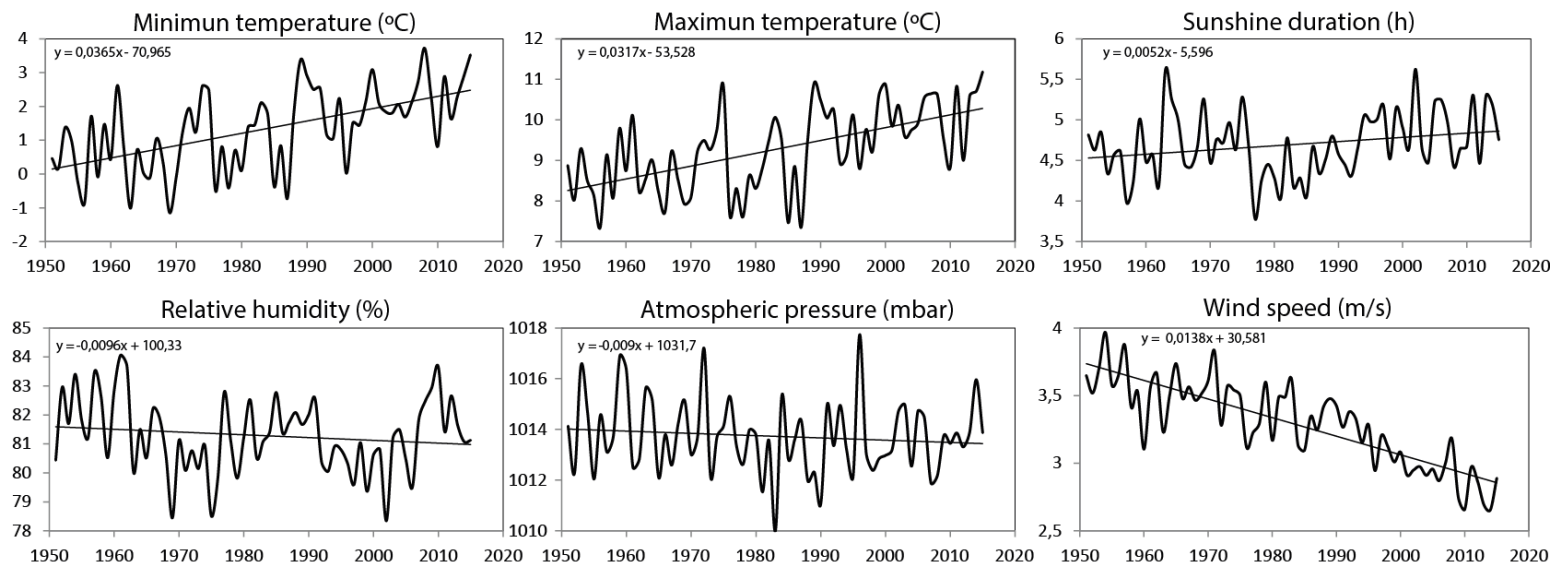

Figure 2. Meteorological variables for the country-scale time series from 1951-2015.

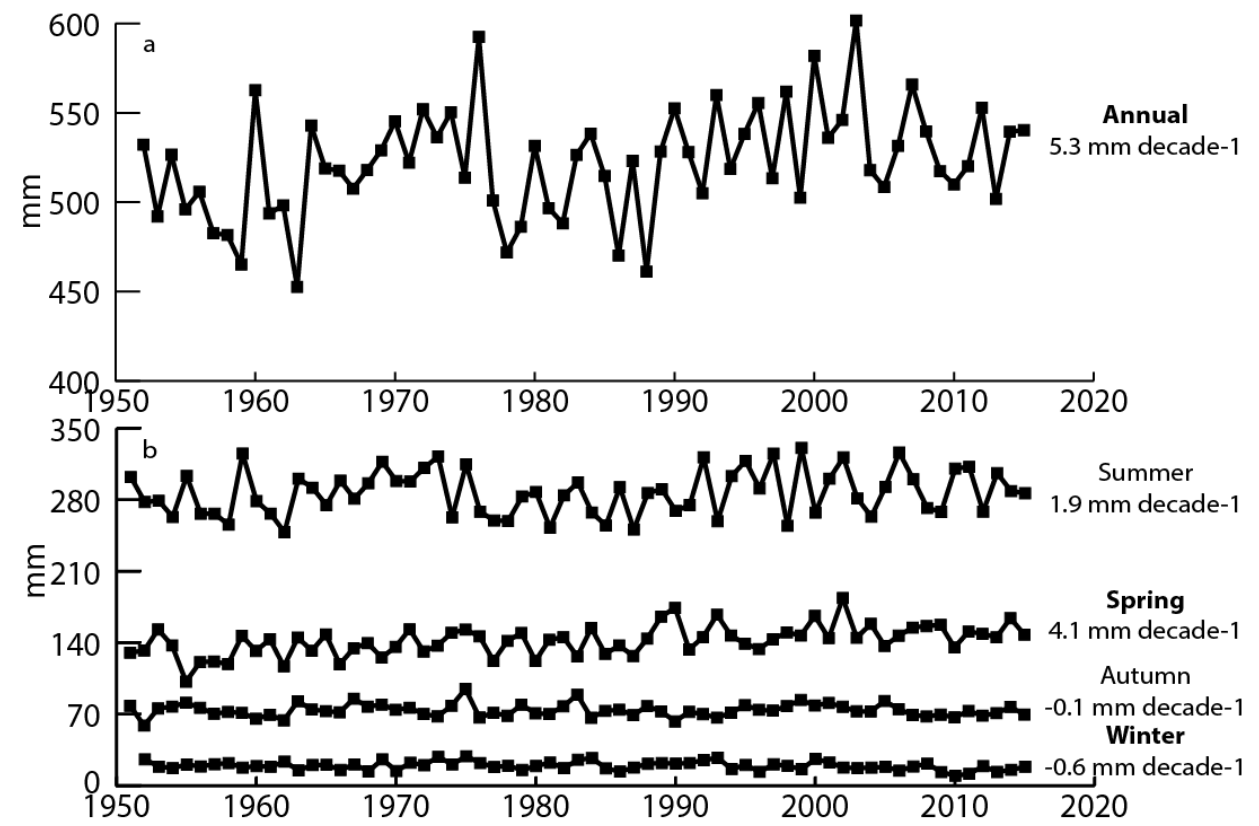

Figure 3. ETo country series at a) annual b) seasonal scale from 1951 to 2015. Significant magnitudes of change are in bold. 
The 1st International Electronic Conference on Hydrological Cycle (CHyCle-2017), 12 - 16 November 2017; Sciforum Electronic Conference Series, Vol. 1, 2017

High significant correlation coefficient (Table 1 ) has been found among computed ETo and observed Epan during the period 1968-2005.

Table 1. Summer Pearson's coefficient between ETo and observed $\mathrm{E}_{\mathrm{pan}}$

\begin{tabular}{ccc}
\hline Station & Period & $\begin{array}{c}\text { Summer (Pearson's } \\
\text { coefficient) }\end{array}$ \\
\hline Kuusiku & $1988-2005$ & 0.79 \\
\hline Tiirikoja & $1989-2005$ & 0.69 \\
\hline Tooma/ Jogeba & $1968-1996$ & 0.78 \\
\hline
\end{tabular}

Figure 4 evaluates the meteorological drivers of ETo. Annual ETo shows high correlation with sunshine duration (positive correlation), relative humidity (negative correlation) and maximum temperature (positive correlation). Spring ETo shows strong correlation with maximum temperature (positive) and relative humidity (negative). Summer $\mathrm{ET}_{0}$ shows the strongest correlation with sunshine duration, although its correlation with maximum temperature and relative humidity is also high. On the other hand winter $\mathrm{ET}_{0}$ shows maximum correlation with wind speed (positive). Meanwhile autumn shows weak correlation coefficients with all the studied variables.
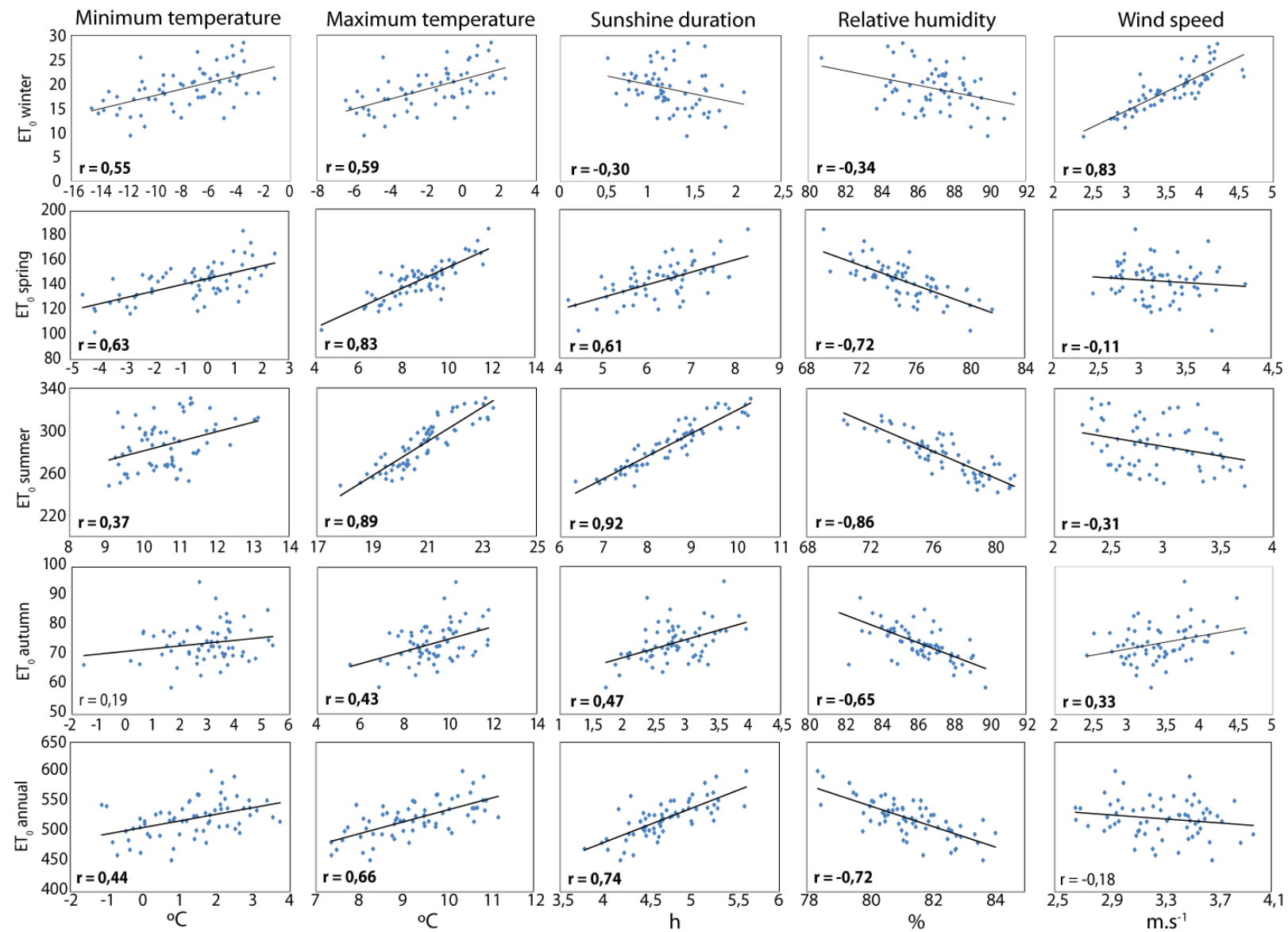

Figure 4. Relationship between country ETo and meteorological variables. Pearson's coefficients in bold are statistically significant at the $95 \%$ confidence level. 
The 1st International Electronic Conference on Hydrological Cycle (CHyCle-2017), 12 - 16 November 2017; Sciforum Electronic Conference Series, Vol. 1, 2017

\section{Discussion and Conclusion}

AED variability in Estonia has been analysed for the first time. At annual scale and country level, $\mathrm{ET}_{0}$ shows a positive and significant trend with a magnitude of change of $5.3 \mathrm{~mm}$ decade- 1 . This contrast with Golubev et al. [3] results, they found negative trends for Epan for the Siberia and North European Russia region. It is important to note that Golubev et al. [3] trend was calculated for the period 1950 to 1990 and for a much larger region. This disagreement points out that more studies are required in order to understand the AED trends and variability in latitudes above $55^{\circ} \mathrm{N}$.

In Estonia the highest seasonal positive trends of $\mathrm{ET}_{0}$ have been found during the spring (4.1 $\mathrm{mm}$ decade-1) and the highest negative in winter (-0.6 mm decade- 1$)$. During the spring the more correlated meteorological variables with $\mathrm{ET}_{0}$ are maximum temperature (positive) and relative humidity (negative). On the other hand, winter $\mathrm{ET}_{0}$ has the greatest correlation with wind speed (negative). Taking into account that the maximum temperatures have a strong positive trend in Estonia and globally [2], it will be probable that ETo continues increasing in Estonia during the spring. Furthermore, an increase of ETo during the winter in Estonia is also expected if the strong negative wind speed trend continues.

Acknowledgments: The authors want to thank the EU and Spanish Ministry of Economy and Competitiveness for funding within the framework of the collaborative international consortium IMDROFLOOD financed under the ERA-NET Cofund WaterWorks2014 Call, an integral part of the 2015 Joint Activities conducted by the Water Challenges for a Changing World Joint Programme.

Author Contributions: All the authors contributed equally to the manuscript.

Conflicts of Interest: The authors declare no conflict of interest.

\section{Abbreviations}

The following abbreviations are used in this manuscript: AED: Atmospheric evaporative demand.

Epan: Pan evaporation.

ETo: Reference evapotranspiration.

FAO: Food and Agricultural Organization.

HOMER: HOMogenization softwarE in R.

\section{References}

1. McVicar T.R., Roderick M.L., Randall D.J. et al., Global review and synthesis of trends in observed terrestrial near-surface. Journal of Hidrology 2012, 416-417, 182-205.

2. Hartmann, D.L., A.M.G. Klein Tank, M. Rusticucci, L.V. Alexander, S. Brönnimann, Y. Charabi, F.J. Dentener, E.J. Dlugokencky, D.R. Easterling, A. Kaplan, B.J. Soden, P.W. Thorne, M. Wild and P.M. Zhai, 2013: Observations: Atmosphere and Surface. In: Climate Change 2013: The Physical Science Basis. Contribution of Working Group I to the Fifth Assessment Report of the Intergovernmental Panel on Climate Change [Stocker, T.F., D. Qin, G.-K. Plattner, M. Tignor, S.K. Allen, J. Boschung, A. Nauels, Y. Xia, V. Bex and P.M. Midgley (eds.)]. Cambridge University Press, Cambridge, United Kingdom and New York, NY, USA.

3. Golubev V.S., Lawrimore J.H., Groisman P.Y. et al. Evaporation changes over the contiguous United States and the former USSR: A reassessment. Geophysical Research Letter 2001, 28, 2665-2668.

4. Mestre O., Domonkos P., Picard F., et al. HOMER: a homogenization software- methods and applications. IDÖJÁRÁS Quarterly Journal of the Hungarian Meteorological Service 2013, 117(1).

5. Allen, R. G. Pereira, L. S., Raes, D., and Smith, M.: Crop evapotranspiration: Guidelines for computing crop water requirements, Food and Agricultural Organization (FAO), Irrig. Drain. pap. 56, Rome, 1998. 
The 1st International Electronic Conference on Hydrological Cycle (CHyCle-2017), 12 - 16 November 2017; Sciforum Electronic Conference Series, Vol. 1, 2017

6. Vicente-Serrano S.M., Azorin-Molina C., Sanchez-Lorenzo A. et al. Reference evaporation variability and trends in Spain, 1961-2011. Global and Planetary Change 2014, 121, 26-40.

(C) 2017 by the authors; licensee MDPI, Basel, Switzerland. This article is an open access article distributed under the terms and conditions of the Creative Commons by Attribution (CC-BY) license (http://creativecommons.org/licenses/by/4.0/). 